\title{
Professores, tecnologias digitais e a distração concentrada
}

\section{Teachers, digital technologies and concentrated distraction}

\author{
Vânia Gomes Zuin ${ }^{1}$ \\ Antônio Álvaro Soares Zuin²
}

\begin{abstract}
RESUMO
Os estudos das influências das novas tecnologias, presentes tanto na formação docente quanto em sua prática, têm sido objeto de muitas pesquisas na área de educação. Diante desse quadro, tem-se como objetivo investigar o modo como as novas tecnologias modificam a prática docente, principalmente no contexto atual, em que predomina a chamada distração concentrada nos processos de ensino e aprendizagem. Parte-se do pressuposto de que refletir sobre as relações entre tais tecnologias, os professores e os processos de ensino e aprendizagem implica considerar a redefinição imagética do professor, bem como dos métodos historicamen-te empregados para promover a disciplina e a concentração entre os estudantes.

Palavras-chave: teoria crítica; indústria cultural; memória; tecnologias digitais; distração concentrada.
\end{abstract}

\begin{abstract}
The studies of influences of new technologies, presented in teacher education as well as in its practice, have been the subject of many researches
\end{abstract}

\footnotetext{
${ }^{1}$ Pós-Doutora em Química pela Universidade de São Paulo (IQSC-USP-2004), e pelo Centro de Pesquisas Ambientais - Helmholtz-Zentrum für Umweltforschung/UFZ - Alemanha (2005), com apoio da Fundação Alexander von Humboldt (AvH). Atualmente é professora doutora da Universidade Federal de São Carlos junto ao Departamento de Química (Adjunta II), credenciada ao Programa de Pós-Graduação em Química e ao Programa de Pós-Graduação em Educação da Universidade Federal de São Carlos, Brasil.

${ }^{2}$ Pós-Doutor em Filosofia da Educação pela Universidade de Leipzig, Alemanha. Professorassociado do Departamento de Educação e do Programa de Pós-Graduação em Educação da Universidade Federal de São Carlos, Brasil. É bolsista de produtividade em pesquisa do CNPq desde 2003, atualmente com o nível 1C.
} 
in the field of education. In this context, it is our aim to examine how new technologies modify teaching practices, especially in the nowadays context where the so called concentrated distraction predominates in teaching and learning process. Starting from the presupposed that to think about the relations among these technologies, teachers and process of teaching and learning it implies to consider the redefinition of the teacher's image, as well as the methods historically used to promote discipline and concentration among students.

Keywords: critical theory; cultural industry; memory; digital technologies; concentrated distraction.

\section{Introdução}

As instituições sociais e culturais que compõem a chamada superestrutura se modificaram, via de regra, de forma mais gradual quando comparadas ao processo de desenvolvimento das relações de produção e das forças produtivas, notadamente as tecnológicas (BENJAMIN, 1985, p. 165). Mas, na sociedade hodierna, caso as relações que se desenvolvem nas instituições supraestruturais não se modifiquem na mesma velocidade das transformações tecnológicas, elas correm o risco de desaparecer ou então de sofrer sérios prejuízos. Por exemplo, aquele que não domina as operações do novo programa de computador pode muito bem não ter o tempo necessário para aprender a fazê-lo e, assim, perder uma excelente oportunidade profissional. A mesma oportunidade que pode ser desperdiçada se determinado e-mail não for respondido a tempo ou então ser inadvertidamente deletado em meio a vários spams que são cotidianamente recebidos. Além disso, não é incomum a frustração da pessoa que não recebe uma resposta imediata de uma mensagem eletrônica enviada, pois pode muito bem deduzir que aquele que tarda a responder não se sente, literalmente, ligado a ela, como se não houvesse, portanto, um link entre ambos. Decididamente, tanto os dilemas quanto as benesses concernentes à diferença de velocidade entre as relações supraestruturais e o binômio relações de produção e forças produtivas se espraiam para todas as esferas, notadamente para a educacional. Por meio do uso das novas tecnologias digitais, é possível acompanhar a trajetória do pensamento de Freud sobre as características do aparelho psíquico, bastando acionar o comando de busca e digitar os conceitos de id, ego e superego. Ou seja, o trabalho de pesquisa de tais conceitos, que levaria meses ou anos para ser feito, pode ser reduzido para semanas, dias ou horas.

Como se pode observar, não é possível mensurar com exatidão os incontáveis ganhos acumulados por meio do desenvolvimento das tecnologias 
digitais, frutos da chamada revolução microeletrônica. Porém, mesmo diante de tantos benefícios, que aparentam confirmar a concretização do escopo inicial da ciência de contribuir decisivamente para amainar o cansaço físico e mental, observa-se também, na esfera educacional, o incômodo dos professores diante dos estudantes que têm grandes dificuldades de se concentrar no aprendizado dos conteúdos que são rapidamente acessados por meio de seus computadores. A atitude de proibição do uso de aparelhos celulares nas escolas sinaliza o desespero dos docentes, cuja força da imagem se arrefece na mesma proporção que recrudesce a potência dos estímulos audiovisuais que se tornam incrivelmente mais sedutores para os estudantes do que as imagens de seus professores.

Diante desse contexto de vício de tais estímulos, insere-se o objetivo desse artigo: investigar o modo como as novas tecnologias modificam a prática docente, principalmente na sociedade atual, em que predomina a chamada distração concentrada nos processos de ensino e aprendizagem. Portanto, refletir sobre a relação entre tais tecnologias, os professores e os processos de ensino e aprendizagem implica considerar a redefinição imagética do próprio professor, bem como dos métodos historicamente empregados para promover a disciplina e a concentração entre os estudantes.

\section{Imagem do professor, disciplina e concentração}

Na leitura dos compêndios de história da educação, se notabiliza a violência exercida pelos educadores nos educandos, cujo emprego foi justificado mediante o propósito de promover a concentração nos conteúdos estudados. Evidentemente, as relações entre professores e estudantes não pode ser exclusivamente caracterizada como uma relação de ódio e ressentimento, pois desde os seus primórdios já se pode observar manifestações de afago e respeito entre mestres e discípulos, haja vista, por exemplo, a relação afetuosa, identificada por Platão, entre Sócrates e seus pupilos. Ainda que em certas ocasiões Sócrates respondesse sarcasticamente aos seus interlocutores que o destratavam, e não esqueçamos que, etimologicamente, sarcasmo significa arrancar carne, nota-se que, de forma geral, prevaleceu nos diálogos socráticos a ironia amorosa que açulava os discípulos a refletir sobre as várias interpretações que os conceitos poderiam ter. Ao invés de se aferrarem à aparência dos conceitos, os discípulos eram estimulados, por meio da refutação e da maiêutica socrática, a se aproximar das essências dos conceitos do belo, da justiça e da virtude. Eles eram incentivados a rememorar afetivamente os conhecimentos que se encontravam nas suas respectivas almas, de modo que, ao contactá-los, fossem 
capazes de guardá-los no coração, de decorá-los. Ou seja, a memória, a mãe de todas as musas (PLATÃO, 2008, p. 62), desempenharia papel fundamental nesse processo de recuperação da essência dos conceitos, de tal maneira que a recuperação mnemônica da verdade de tal aparato conceitual engendraria uma sensação prazerosa difícil de ser mensurada ou mesmo descrita.

Contudo, não foi a ironia amorosa que preponderou nas relações pedagógicas instituídas na Antiguidade greco-romana. Manacorda destaca o modo como o liame entre dor e memorização de conteúdos sobrelevou-se em relação ao propósito socrático de que o discípulo deveria ser estimulado a desenvolver sua capacidade mnemônica para a compreensão da essência dos conceitos Na leitura do livro História da educação: da Antiguidade aos nossos dias, é interessante notar como o educador italiano relaciona o tédio gerado pela didática cada vez mais repetitiva, que se fundamentava no aprendizado de conteúdos muitas vezes alheios aos interesses dos estudantes, com o sadismo pedagógico generalizado (MANACORDA, 1986, p. 93). A relação entre sadismo e memorização dolorosa de conteúdos é muito mais remota do que essa prática "educacional" presente nas relações professor-estudante da Antiguidade greco-romana. Nietzsche já identificara tal relação na pré-história do ser humano, principalmente quando ressaltou o modo como determinados conteúdos foram retidos na consciência. Justamente no transcorrer do exercício das práticas sacrificiais, o ser humano pôde aprimorar sua mnemotécnica, mas isso à custa de um preço muito alto, pois a sensibilização humana para a apreensão de determinados conteúdos fora possível mediante o desenvolvimento da dessensibilização diante da dor. Nietzsche afirma que "[...] talvez nada exista de mais terrível e inquietante na pré-história do homem do que sua mnemotécnica. Grava-se algo a fogo para que fique na memória: apenas o que não cessa de causar dor fica na memória - eis um axioma da mais antiga (e infelizmente mais duradoura) psicologia da terra" (NIETZSCHE, 1998, p. 50; grifos do original).

Se apenas o que não cessa de causar dor permanece na memória, sendo esse o axioma da mais antiga psicologia da terra, não menos relevante é a consequência pedagógica dessa observação de Nietzsche sobre a relação entre dor, memória e aprendizado. De forma geral, a presença dessa tríade pode ser observada no transcorrer do desenvolvimento histórico das práticas pedagógicas, embora as ênfases dos processos punitivos pendessem, em certos momentos, ora para a aplicação da violência física, ora para o emprego da violência psicológica. É difícil discernir a presença exclusiva de uma em relação à outra. Dar a mão à palmatória implicava, por exemplo, tanto na sensação de dor física decorrente das pancadas feitas pelo professor quanto no mal-estar de ser 
humilhado pelo professor diante dos demais colegas. Não por acaso, a expressão dar a mão à palmatória se transformou no adágio de que aquele que assim procede reconhece seu comportamento inadequado. Embora fosse impossível identificar a presença exclusiva da violência física ou da simbólica nos castigos aplicados, torna-se cada vez mais presente, na história da prática pedagógica, a preocupação de se restringir a execução de castigos físicos nas salas de aula. Tal preocupação pode ser observada tanto nas regras de conduta da Ratio Studiorum jesuítica - por meio das quais se constata que os castigos físicos só seriam aplicados em último caso e nunca pelo professor, mas sim por uma espécie de corretor -, quanto nas críticas de Locke (1986, p. 108-109) e Comênio (1985, p. 403) referentes ao uso do artifício da punição física, utilizado pelo professor como recurso para que pudesse obter o respeito e a disciplina do alunado.

O estabelecimento de tais restrições às práticas de punição física nos estudantes também delineia os contornos das punições psicológicas que gradativamente consolidaram sua hegemonia no decorrer das atividades do cotidiano escolar. E é interessante observar que tanto os jesuítas quanto Locke e Comênio destacaram o professor como o centro do processo educacional/formativo, de modo que os estudantes deveriam internalizar a necessidade de ser disciplinado como condição de poder se aproximar do professor, considerado $o$ modelo a ser seguido. Na vertente sacra da chamada pedagogia humanista tradicional, aqui representada pelos jesuítas, os padres/professores representavam Deus na terra e, portanto, modelos de conduta a serem seguidos pelos estudantes. Já na vertente leiga da mesma corrente pedagógica, a imagem do professor deveria servir para "afirmar a superioridade sobre as crianças para que tornasse sensível uma força formativa” (HERBART, 2003, p. 188). Pois, para Herbart, o professor precisaria ser identificado pelo estudante como o agente capaz de lhe antecipar, de acordo com a expressão de Herbart, os objetivos do homem futuro. Mas, para que isso ocorresse, tanto o professor quanto o estudante deveriam manter uma distância que lhes permitisse conservar suas respectivas identidades:

Não é evidente a distância entre o adulto e a criança? [...] Por isso previnemse os educadores para que desçam ao nível das crianças e se integrem, custe o que custar, na estreita esfera daquelas. E aqui não se atende aos novos e inúmeros erros que com isso se cometem! Ignora-se que se exige o que não deve ser, algo que a natureza inevitavelmente penaliza, porque está a pretender-se que um adulto desça ao nível da criança e, desse modo, construa um mundo infantil! (HERBART, 2003, p. 20).

É importante observar que os grifos foram feitos pelo próprio Herbart. Ou seja, é como se ele precisasse enfatizar a importância da distância entre os 
agentes educacionais como condição do desenvolvimento educacional/ formativo de ambos. E se Herbart pôde ser distinguido como um dos principais representantes da denominada pedagogia humanista tradicional, Rousseau, o chamado iluminista "herético", foi considerado por muitos como o fundador da chamada pedagogia humanista moderna. No seu romance de formação Emílio, ou da educação, o fillósofo genebrino apresenta ao leitor seus pressupostos para a confecção de um processo formativo ideal, profundamente balizado na crítica à aparência de moralidade da educação vigente, que formava um homem hipócrita, pois esse homem repetia palavras de ordem aprendidas, mas não as internalizava em seu coração, não as decorava, de acordo com o sentido socrático-platônico anteriormente colocado. Frente a tal hipocrisia, Rousseau defendeu a urgência de se respeitar as diferentes fases do desenvolvimento psicofísico dos estudantes para que eles memorizassem conteúdos adequados às etapas de seus desenvolvimentos físico, cognitivo e afetivo. Além disso, ele também destacou a necessidade de uma maior aproximação do professor em relação ao estudante como condição para o desenvolvimento de ambos no decorrer do processo de ensino e aprendizagem. De fato, a defesa de uma maior aproximação entre professores e estudantes, tal como enfatizou Rousseau, não pôde ser apartada do espírito de um tempo que exaltava cada vez mais os benefícios do pensamento objetivado nas experiências humanas como condição de maior incremento do processo produtivo. "Viver não é respirar, é agir" (ROUSSEAU, 1992, p. 16), essa máxima pedagógica de Rousseau referendou não só relevância das ações humanas como produtoras dos conhecimentos que as aprimorariam como também corroborou a maior aproximação do professor em relação ao estudante para que tais ações ressignificassem suas respectivas identidades de agentes educacionais. Mas talvez o próprio Rousseau se espantasse com aquilo que estaria por vir nas primeiras décadas do século XX, ou seja, o modo como as forças produtivas tecnológicas determinariam modificações profundas nas estruturas identitárias e imagéticas dos agentes educacionais.

\section{As tecnologias digitais e a hegemonia da distração concentrada}

Dentre vários pensadores cujas obras versam sobre a relação entre o desenvolvimento científico e tecnológico e processos de ensino e aprendizagem, destacam-se as concepções de John Dewey. É sintomática a forma como Dewey finaliza o capítulo "A criança e o programa escolar", de seu livro Vida e educação, pois ele conclama ao educador que estimule o estudante, por meio de sua própria atividade, a se interessar pelos conteúdos das matérias que lhes 
são apresentados pelo mestre, de tal modo que o estudante "cumpra seu destino, tal qual é revelado nos tesouros de ciência, de arte e de indústria, ora existentes no mundo" (DEWEY, 1978, p. 62). Partindo desse pressuposto, o desenvolvimento da memorização não deveria ser identificado pelo alunado como algo absolutamente doloroso. Caso isso acontecesse, certamente eles próprios esqueceriam rapidamente os conteúdos, pois, na linguagem de Dewey, não se sentiriam estimulados a reorganizar suas próprias experiências a ponto de verdadeiramente assimilá-los. De fato, um dos aspectos mais interessantes na proposta educacional de Dewey é mesmo a articulação por ele estabelecida entre educação, indústria e desenvolvimento científico. Para que as relações entre esses três elementos engendrassem frutos portentosos, seria absolutamente necessário que a experiência formativa e a ciência se aproximassem cada vez mais, pois justamente tal proximidade permitiria não só uma melhor compreensão das questões sociais, como também possibilitaria a construção de uma ordem social melhor (DEWEY, 2010, p. 22).

Dewey sustentou a existência de tais ideias no final da década de 1930 , um período marcante, principalmente em função do fato de que a chamada revolução técnico-científica cada vez mais impulsionava o desenvolvimento das relações de produção do capitalismo monopolista. Foi nesse período que o desenvolvimento científico passou a ser controlado mais de perto, pois seus produtos seriam decisivos para fomentar a aproximação das empresas que formariam os grandes trustes. As fusões dos conglomerados empresariais não ocorreriam caso não houvesse a aplicação de volumosos investimentos de capital no controle da produção científica. E quando a tecnologia se transforma na, por assim dizer, menina dos olhos do capital, consolida-se a chamada revolução técnico-científica, cujos ecos ressoaram no transcorrer dos anos com intensidade cada vez maior.

Uma forma de reverberação desses ecos pode ser observada no modo como, décadas após esse texto de Dewey, Skinner enfatizou o emprego de recursos tecnológicos para o desenvolvimento das etapas do processo de ensino e aprendizagem. As chamadas máquinas de ensinar, as quais foram também utilizadas durante o período da ditadura militar no nosso país, seriam, ao ver do psicólogo estadunidense, imprescindíveis para o progresso do aprendizado dos conteúdos das mais variadas disciplinas. De forma geral, tais máquinas funcionavam da seguinte maneira: os estudantes que respondiam corretamente a certas questões recebiam um sinal de aprovação como reforço positivo. Caso respondessem de forma equivocada, deveriam realizar novas tentativas até que obtivessem sucesso e, assim, passassem para a pergunta seguinte. É interessante observar o modo como a possível passividade do estudante - que poderia se 
tornar condicionado a responder corretamente sem que precisasse se esforçar para compor a resposta -, deveria ser evitada, segundo Skinner, por meio da utilização de novas tecnologias. Ou seja, deveriam ser produzidas novas máquinas capazes de avaliar tal composição (SKINNER, 1972, p. 32). O psicólogo tinha consciência da necessidade imperiosa de o estudante se esforçar para que ocorresse verdadeiramente algum aprendizado, pois não bastava receber um reforço positivo imediato por meio da luz verde que se acendia mediante a resposta correta. $\mathrm{Na}$ verdade, o estudante precisaria se concentrar na elaboração de sua resposta para que houvesse a memorização do conteúdo aprendido.

Mas se Skinner reconheceu a importância do papel do professor na sua relação com os estudantes, através de "contatos intelectuais, culturais e emocionais" (1972, p. 25), ele também destacou o fato de que a grande vantagem do uso da máquina seria a imediaticidade da conferência da resposta do estudante e, portanto, da rapidez de aplicação do reforço positivo. Justamente por ter vários estudantes, os professores demorariam muito para poder reforçar positivamente os comportamentos de cada um deles. Exatamente por sua complexidade e sutileza, o organismo humano seria mais eficazmente controlado pelas máquinas do que por outros seres humanos. Já em meados da década de 1960, Skinner asseverava o seguinte: "Há, portanto, todas as razões para esperar que um controle mais eficaz da aprendizagem humana exija recursos instrumentais. O fato puro e simples é que, na realidade de mero mecanismo reforçador, a professora está fora de moda" (SKINNER, 1972, p. 20). Assim, a máquina teria um papel muito mais decisivo como mecanismo reforçador do comportamento de aprendizagem do estudante do que sua professora ou professor, de carne e osso. O fascínio que os aparatos tecnológicos exercem não pode ser exclusivamente creditado a Skinner, pois trata-se, primeiramente, do modo como as relações de produção humanas convertem a tecnologia não mais como "apenas" um conjunto de técnicas, mas sim como um processo social que engendra, numa escala de produção geométrica, pessoas tecnologizadas.

Günther Anders cunhou o conceito de vergonha prometeica com o objetivo de compreender as características da tecnologia entendida como processo social. Ao aludir ao mito de Prometeu, que roubou dos deuses a técnica da produção do fogo e a entregou aos seres humanos, Anders afirma que o ser humano atual se incomoda em "apresentar, diante dos olhos dos aparelhos perfeitos, sua patética condição de ser carnal, a imprecisão de sua condição humana. Na verdade, ele tinha mesmo que se envergonhar diante disso" (ANDERS, 2002, p. 23).

Justamente por se envergonhar de sua condição de fragilidade e de sua existência perene, o ser humano, ao invés de refletir sobre suas próprias fra- 
quezas, já que a vergonha é um sentimento de conotação moral, opta por se assemelhar cada vez mais aos seus produtos, ao viver e produzir no ritmo das máquinas. A vergonha sentida passa a ser compensada por uma entrega, por assim dizer, de corpo e alma, ao sortilégio da força, durabilidade, precisão e infalibilidade da máquina. Mas o que dizer da atualidade de tal fetiche, cuja sedução se esteia no espaço virtual que potencializa incomensuravelmente a realização de desejos narcísicos de onipotência? Na esfera da educação, por exemplo, a exposição de tal desejo se expressa nas imagens dos trotes universitários que são postadas no Youtube e que competem entre si para angariar mais internautas, cujos números correspondentes às visitas virtuais são cotidianamente renovados e registrados nos cantos dos vídeos nos quais os veteranos humilham e, até mesmo, ferem fisicamente seus calouros. A transformação da fúria narcísica de tal estudante num estímulo audiovisual espetacular nos revela muito sobre o modo como nos viciamos freneticamente pelo consumo de tais estímulos, os quais se tornam mais agressivos para que possam ser consumidos. Não por acaso a tela da televisão se universaliza de forma onipresente em praticamente todas as relações sociais. E é justamente a possibilidade de acessarmos uma quantidade inacreditável de informações, por meio das atuais tecnologias digitais, que porta consigo a contradição de nos depararmos com infinitos conhecimentos e possibilidades de relações de forma on line e instantânea e, ao mesmo tempo, não conseguirmos nos concentrar para que construamos representações mentais que durem o tempo necessário para a formação dos conceitos. Diante da oferta monumental de informações obtidas por meio dos meios de comunicação de massa, principalmente a internet, o indivíduo foca sua atenção por pouquíssimos instantes nos dados expostos nas telas dos computadores, uma vez que novos links como que clamam para serem acessados. Contudo, a qualidade dessas ligações muitas vezes contrasta com a quantidade das informações, as quais dificilmente são assimiladas, pois não há o tempo e nem o esforço necessários para que o indivíduo possa estabelecer relações entre os conceitos de modo a tencioná-los e, assim, criar uma miríade de novos significados.

Não é fortuito o fato de que os indivíduos têm contumazes dificuldades de concentração, principalmente quando se "conectam" com outras pessoas e, ao mesmo tempo, leem informações nos mais variados sítios de notícias. É como se as caixas de e-mails nos chamassem a todo instante para que suas mensagens fossem imediatamente lidas e respondidas. Também não é obra do acaso a utilização de termos tais como: "conectar", "lincar" e "desligar" - esse último o mais difícil de ser concretizado, diga-se de passagem - para designar relações entre pessoas, numa clara atualização do conceito de vergonha 
prometeica, tal como foi anteriormente exposto. Christoph Türcke denominou esse fenômeno da dificuldade de concentração, na sociedade da audiovisuabilidade total, de distração concentrada.

De modo fulminante, o choque (audiovisual) concentra a atenção num ponto, para poder triturar essa concentração através de incontáveis repetições. O meio de concentração é, propriamente, o meio de decomposição [...]. A tela, o grande recheio do tempo livre, penetrou profundamente, por meio do computador, no mundo do trabalho; a coordenação de processos inteiros de produção e administração perpassa por ela, de tal modo que se apresenta como o ensino do futuro (TÜRCKE, 2010, p. 266-267).

Mas o ensino do futuro já cobra seus dividendos no nosso presente, uma vez que o emprego das novas tecnologias digitais reconfigura cotidianamente as identidades dos professores e dos estudantes e, portanto, a própria prática docente. Recentemente, fez sucesso uma propaganda de impressora cujo cenário era exatamente uma sala de aula. O professor pedia aos seus estudantes para que produzissem um texto sobre animais. Um dos estudantes escreveu uma redação de próprio punho e a entregou com trajes de menino das cavernas. $\mathrm{O}$ olhar de censura do professor fez com que o estudante voltasse para casa, digitasse a palavra animais num sítio de busca da internet e imprimisse pilhas de imagens e textos sobre macacos, leões, girafas etc. Aí sim ele foi recompensado pelo professor. O sucesso de tal propaganda confirma o quanto tal prática se universaliza e se torna comum nas instituições escolares, desde o ensino fundamental até o superior. $\mathrm{E}$ isso ocorre, em muitas ocasiões, sob o olhar conivente do professor. Nem mesmo Skinner imaginaria uma situação como essa, na medida em que ele mesmo se aferrou à defesa de que os professores deveriam estimular a composição das respostas de seus estudantes, pois sabia muito bem a relevância do esforço do estudante em relacionar as informações recebidas para a elaboração e a memorização dos conceitos. Dito de outro modo, dificilmente ocorre aprendizado caso as representações mentais não sejam confrontadas entre si, para que, desse confronto, novos conceitos possam ser originados.

A sutileza da dança das palavras perde seu compasso quando são apenas copiadas e coladas num texto, cujas cores e tamanhos de fonte que as compõem como que berram para serem ouvidas e percebidas pelos leitores. Freud chamou nossa atenção quando, em seu livro $O$ mal-estar na civilização, nos disse que as tecnologias da fotografia e do gramofone nada mais eram do que materializações da memória, pois eram capazes de reter, respectivamente, as fugidias impressões visuais e auditivas (FREUD, 1997, p. 43). Ironicamente, em tempos 
de universalização da distração concentrada no capitalismo globalizado, o atual mal-estar concerne ao fato de que a forma hegemônica de utilização das tecnologias digitais dificulta a permanência de nossa concentração em seus produtos e, portanto, da memorização dos conteúdos informacionais. Ou seja, a capacidade de concentração se torna cada vez mais fugidia diante da oferta infindável de informações que atualmente dispomos. Tal raciocínio poderia ser equivocadamente interpretado como uma espécie de defesa da não utilização de tais tecnologias. Se fosse esse o caso, seria o mesmo que negar o potencial emancipatório que a tecnologia, enquanto produção historicamente humana que é, conserva consigo, tal como foi anteriormente enfatizado. Mas, em muitas ocasiões, a presença desse potencial emancipatório parece chocar o professor, a ponto de provocar entraves no desenvolvimento do próprio processo de ensino e aprendizagem.

Diante de uma dúvida exposta pelo estudante que acessa a internet na sala de aula, o professor pode se comportar de várias formas. Ele pode, por exemplo, fingir que responde à questão e, no meio da elaboração do raciocínio, tergiversar para outro assunto. Além disso, o professor pode simplesmente dizer ao estudante que o assunto não é relevante, se esquivando não só da resposta, como também da dura admissão de que a desconhece. Mas, será que assumir o próprio desconhecimento implica, diante dos olhos dos estudantes, uma falha imperdoável, uma vez que o professor tem que vergonhosamente admitir que é um ser humano, sujeito a falhas e acertos, como outro qualquer? Qual seria o problema de assumir tal falibilidade tão humana? E mais: será que as tecnologias digitais não poderiam ser utilizadas justamente para promover a permanência da concentração de tais agentes educacionais numa determinada informação, a ponto de, gradativamente, suscitar aquele movimento espetacular da metamorfose da informação em formação cultural? Frente à dúvida do estudante, que poderia muito bem ser uma dúvida do professor, por que ambos não poderiam empregar os recursos da internet para conjuntamente dirimi-la? Por que ambos não poderiam se concentrar na informação obtida e juntos refletirem sobre possíveis respostas? Essas são questões difíceis de serem respondidas. E tal dificuldade advém não tanto da certeza íntima de que os recursos das tecnologias digitais poderiam ser utilizados para a promoção de práticas educacionais emancipatórias, mas sim do fato de que a atual disseminação de tais tecnologias reconfigura também as relações de poder, inclusive as que se desenvolvem na esfera educacional. Por meio da própria internet, somos cotidianamente notificados não só da tentativa de governos ditatoriais de enfraquecer rebeliões mediante o pretenso controle das tecnologias digitais, como também temos contato com as imagens e notícias dos próprios rebeldes, cujas 
manifestações populares são inevitavelmente postadas no Youtube e nas redes sociais.

No que diz respeito às reconfigurações identitárias dos agentes educacionais, particularmente em relação à nova prática docente, nos deparamos com uma questão decisiva: o papel do professor diante do acesso cada vez maior de informações, as quais são instantaneamente obtidas por aparelhos tais como notebooks, tablets, celulares etc. Foi observada, anteriormente, a crítica de Herbart sobre a relevância do professor se manter distanciado em relação ao estudante, pois, caso contrário, ele não poderia se apresentar como modelo a ser seguido, sendo essa uma condição fundamental para que o estudante desejasse se apropriar dos códigos informacionais que, gradativamente, lhe capacitariam a ocupar o lugar do mestre no futuro. Porém, tal distância parece se reduzir cada vez mais com passar do tempo e isso ocorre principalmente porque as revoluções das forças produtivas, notadamente as de ordem tecnológica, determinam o modo como se abreviam os intervalos formativos observados entre os professores e os estudantes. Isso significaria, em termos skinnerianos, solapar a capacidade do professor de reforçar o comportamento de aprendizagem do estudante? Pensamos que, atualmente, seja verdadeiro o raciocínio oposto. Talvez nunca a intervenção do professor fosse tão primordial e necessária. $\mathrm{O}$ incômodo maior nos parece ser a percepção dos próprios agentes educacionais de sua condição fragmentada de ser e estar em todos os ambientes, incluindo os virtuais.

Não podemos desconsiderar o fato de que, em tempos de supremacia da chamada distração concentrada, torna-se cada vez mais difícil a produção do raciocínio crítico diante da velocidade da substituibilidade dos estímulos audiovisuais que concentram a atenção de quem os consome para logo em seguida triturá-la. Mas é nesse ponto que a imagem do professor se torna cada vez mais decisiva. No livro Sociedade excitada: filosofia da sensação, Christoph Türcke nos lembra da consideração de Benjamin sobre Marx de que as revoluções seriam a locomotiva da história. Na verdade, afirma Benjamin, talvez elas fossem a forma que a humanidade teria para se agarrar ao freio de emergência das locomotivas (TÜRCKE, 2010, p. 303).

No caso do professor, eis que surge uma poderosa metáfora do seu papel determinante para auxiliar os estudantes a fixar a concentração nos conteúdos a serem aprendidos. A hegemonia da distração concentrada impinge a negação do dito de Karl Kraus de que "quanto mais de perto se olha a palavra, para mais distante ela remete de volta o olhar" (KRAUS, 1986, p. 291). A distração concentrada não permite fazer com que o olhar permaneça vinculado à palavra o tempo necessário para que a própria palavra seja tencionada, a ponto de 
remeter esse olhar para o vislumbre de outros significados. Pois, na sociedade da audiovisibilidade total, apreender um conteúdo torna-se, mais do que nunca, condição fundamental para que ele possar ser de fato aprendido.

Se as atuais novas tecnologias digitais permitem fazer com que olhemos a palavra com uma precisão até bem pouco tempo atrás inimaginável, a imagem do professor se torna decisiva para que os olhares dos estudantes possam ser remetidos para distâncias também cada vez maiores, na medida em que o brilho do dado imediato não exerce o sortilégio de bastar-se a si próprio, mas sim suscita o engendrar de novas interpretações, justamente porque houve o tempo e o esforço necessários para que os agentes educacionais se concentrassem na reflexão dos conteúdos. É dessa forma que o professor também atua como um freio de emergência. E se as reformas pedagógicas sustentadas pelo desenvolvimento tecnológico já haviam, em meados do século passado, arrefecido a imagem de autoridade do professor, pois assim "enfraqueceram mais ainda a dedicação e o aprofundamento íntimo do espiritual, a que estava vinculada a liberdade" (ADORNO, 2010, p. 21), torna-se fundamental a reflexão sobre a importância do professor em tempos nos quais predomina a visão fetichista de que ele deve ser substituído por novas tecnologias que dispensam exatamente sua imagem de autoridade pedagógica.

Contudo, a atual prática docente, que se renova por meio do contato com as tecnologias digitais, também designa transformações fulcrais em relação a esse conceito de autoridade. Não é possível se referir a esse conceito, nos dias de hoje, do mesmo modo como fizeram os pensadores da chamada pedagogia humanista tradicional leiga, tal como no caso de Herbart.

E essa impossibilidade se fundamenta no fato de que as novas tecnologias digitais impingem mudanças na configuração da autoridade do professor em relação aos seus estudantes, principalmente quanto à diminuição da distância entre tais agentes educacionais. Aquilo que fora previsto por Dewey se concretiza de uma maneira irremediável, ou seja, o desenvolvimento científico e tecnológico reorganiza as experiências educacionais de tal forma que o professor precisa não só ouvir, como também considerar os interesses e desejos dos estudantes para que o processo de ensino e aprendizagem se desenvolva. Mas tal proximidade pode tanto se atrelar ao denominado pacto de mediocridade, por meio do qual professores e estudantes fingem que aprendem e ensinam, na medida em que os conteúdos dos trabalhos acadêmicos são copiados e colados nos textos, quanto propiciar condições para que o professor assuma que é falível como qualquer outra pessoa e não refute a informação que o estudante lhe apresenta, através da consulta on line de determinado assunto que está sendo discutido em sala de aula. 


\section{Considerações finais}

O fato que se impõe hoje é o de que os estudantes, de uma forma ou de outra, intervêm cada vez mais no processo de ensino e aprendizagem por meio do uso das tecnologias digitais. E suas intervenções, mediadas por tais tecnologias, podem enveredar para a montagem da foto do professor humilhado, que é postada nos sítios de relacionamento da internet. Ou então para a oferta de outra interpretação sobre determinado tema, interpretação essa que o professor não havia pensado ou mesmo não sabia, fazendo com que ambos revejam seus conceitos preconcebidos. De todo modo, diante da sedução dos estímulos audiovisuais, que parecem reproduzir o real de uma forma tão verossímil - pensemos na atual tecnologia $3 \mathrm{D}$ e naquilo que ainda está por vir -, a ponto de não mais precisarmos pensar, pois tais cenários como que pensam no nosso lugar, a sobrevivência do jogo das representações mentais, que podem se converter em conceitos, se nutre da intervenção do professor como agente de resistência diante do frenesi da distração concentrada.

Os professores, como se fossem verdadeiros freios de emergência, precisam contribuir para que seus estudantes desacelerem seu ritmo, o processo aparentemente inócuo de distração, de tal modo que tenham o tempo e o esforço necessários para pensar criticamente sobre aquilo que aprendem. Seria o caso de o professor estimular, em termos benjaminianos, a conversão da vivência (Erlebnis), o conhecimento assimilado às pressas, em experiência (Erfahrung), ou seja, o conhecimento que se acumula e produz efeitos perenes na consolidação das capacidades mnemônico-afetivas dos estudantes (BENJAMIN, 1991, p. 146). Muito mais do que reações catárticas, as intervenções dos estudantes, emitidas compulsivamente por meio da internet, representam o seguinte: a tentativa de serem percebidos e, assim, permanecer na memória de seus professores. Por meio da utilização das novas tecnologias espetaculares, os estudantes nos mostram que tal proximidade poderá ser obtida tanto de forma violenta quanto por uma aproximação amorosamente mais respeitosa. Pois, em tempos da virtualização que se universaliza para todas as relações, eles nos ensinam que o jogo pedagógico pode ser qualitativamente diferente; que as relações de poder entre professores e estudantes poderiam ser mais humanas, demasiadamente humanas (NIETZSCHE, 2000). E já que usamos essa expressão de Nietzsche, lembremo-nos de outra máxima de sua autoria: "Retribui-se mal um mestre quando se permanece sempre e somente discípulo. E por que não quereis arrancar as folhas de minha coroa?" (NIETZSCHE, 2005, p. 105).

Munidos dos atuais aparatos tecnológicos, os estudantes parecem interpretar literalmente essa provocação do Zaratustra, de Nietzsche, quando rea- 
lizam uma espécie de cyberbullying e postam imagens vexatórias também de seus mestres no Youtube. Mas, se as novas tecnologias digitais portam consigo elementos emancipatórios, o professor precisa se conscientizar de que deve estabelecer uma relação dialógica com seus estudantes, de modo a fazer com que eles o respeitem justamente porque suas intervenções são ouvidas e consideradas. Ironicamente, esse movimento torna-se possível quando o professor exerce seu papel de freio de emergência, pois na sociedade da audiovisibilidade total a expressão "parar para pensar" adquire ares de imperativo categórico. O professor exerce sua autoridade quando estimula, pedagogicamente, esse "parar para pensar" em conjunto com seus estudantes, fazendo com que os acertos e erros de ambos possam ser discutidos coletivamente e não mais dissimulados. Portanto, à revelia da constatação de Skinner, pode-se afirmar que, face às novas tecnologias do ensino e transformações na prática docente, os professores estão cada vez mais na moda.

\section{REFERÊNCIAS}

ADORNO, T. W. Teoria da semiformação. In: PUCCI, B.; ZUIN, A. A. S.; LASTÓRIA, L. A. C. B. (Orgs.). Teoria crítica e inconformismo: novas perspectivas de pesquisa. Campinas: Autores Associados, 2010. p. 7-40.

ANDERS, G. Die Antiquiertheit des Menschen I. München: C. H. Beck, 2002.

BENJAMIN, W. Magia e técnica, arte e política. São Paulo: Brasiliense, 1985. . Charles Baudelaire: um lírico no auge do capitalismo. São Paulo: Brasiliense, 1991.

COMÊNIO, J. A. Didáctica Magna. Lisboa: Fundação Calouste Gulben-kian, 1985 .

DEWEY, J. Vida e educação. São Paulo: Melhoramentos, 1978. . Experiência e educação. Petrópolis: Vozes, 2010.

FREUD, S. O mal-estar na civilização. Rio de Janeiro: Imago, 1997.

HERBART, J, F. Pedagogia geral. Lisboa: Fundação Calouste Gulbenkian, 2003. 
KRAUS, K. Aphorismen. Frankfurt am Main: Suhrkamp Verlag, 1986.

LOCKE, J. Pensamientos sobre la Educación. Madrid: Akal, 1986.

MANACORDA, M. A. História da educação: da Antiguidade aos nossos dias. São Paulo: Cortez e Autores Associados, 1989.

NIETZSCHE, F. Genealogia da moral. São Paulo: Companhia das Letras, 1998. . Humano, demasiado humano: um livro para espíritos livres. São Paulo:

Companhia das Letras, 2000.

. Assim falou Zaratustra. Rio de Janeiro: Civilização Brasileira, 2005. PLATÃO. Diálogos socráticos. Bauru: Edipro, 2008.

ROUSSEAU, J. J. Emílio, ou da educação. Rio de Janeiro: Bertrand Brasil, 1992.

SKINNER, B. F. Tecnologia do ensino. São Paulo: E.P.U., 1972.

TÜRCKE, C. Sociedade excitada: filosofia da sensação. Campinas: Editora da Unicamp, 2010.

Texto recebido em 09 de abril de 2011.

Texto aprovado em 30 de setembro de 2011. 